\title{
The Influence of Pulmonary Rehabilitation and Counselling on Perceptions of Physical Activity in Individuals with COPD - A Qualitative Study
}

\author{
Mandy Scheermesser (D) \\ Leah Reicherzer' \\ Swantje Beyer ${ }^{2}$ \\ David Gisi $\mathbb{1 D}^{3}$ \\ Spencer Rezek ${ }^{3}$ \\ Thomas Hess ${ }^{2}$ \\ Markus Wirz' \\ Anne- \\ Kathrin Rausch Osthoff (ID \\ 'Zurich University of Applied Sciences \\ (ZHAW), School of Health Professions, \\ Institute for Physiotherapy, Winterthur, \\ 8400, Switzerland; ${ }^{2}$ Cantonal Hospital \\ Winterthur (KSW), Pneumology, \\ Winterthur, 840I, Switzerland; ${ }^{3}$ Cantonal \\ Hospital Winterthur, Institute of \\ Physiotherapy, Winterthur, 840I, \\ Switzerland
}

\begin{abstract}
Objective: The aim of this study was to explore to what extent a combined counselling and pulmonary rehabilitation program (PR) influences the perception of physical activity (PA) and motivation for behavioral change in PA in individuals with COPD. The results of previous quantitative trial that investigated the effect of this combined treatment on daily PA were inconclusive. It is conjectured that a more targeted tailoring of the counselling and PR intervention could improve its effectiveness.
\end{abstract}

Patients and Methods: Eighteen individuals with COPD (median age 69, 8 females) who had participated in the PneumoReha program were interviewed twice (following PR and at three-month follow-up). These interviews were transcribed and analyzed thematically. Based on the codes thus identified, three categories 'perception of PA intensity', 'quality of motivation to perform PA', and 'strategies to cope with barriers' were used to differentiate 'types' of participants.

Results: Four different types of COPD individuals were distinguished. Study findings indicate that those individuals who participated in the PR program combined with embedded counselling tended to be more active and intrinsically motivated.

Conclusion: A typology of four types of people with COPD was developed, characterized by their perception of activity, individual motivation and strategies for managing barriers. The patients' physical activity level might be influenced by their concept of physical activity and the quality of motivation. Recognizing patients' different activity behaviors is important for improving the quality of outpatient PR programs and developing tailored (according to each type) counselling interventions embedded in outpatient PR programs.

Clinical Trial Registration: The study was registered on the website of https://www. clinicaltrials.gov/ with the identifier NCT02455206 (27/05/2015), as well as on the Swiss National Trails Portal SNCTP000001426 (05/21/2015).

Keywords: behavioral change, physical activity promotion, COPD, motivational interviewing, qualitative study

\section{Introduction}

Individuals with Chronic Obstructive Pulmonary Disease (COPD) are less engaged in physical activity (PA) than their healthy peers. ${ }^{1}$ Inactivity has been linked to poor disease prognosis (eg higher risk of readmission to hospital, or mortality). ${ }^{2-5}$ Both the American Thoracic Society and the European Respiratory Society have stressed that long-term self-management and adherence to exercise at home should be the primary goals of comprehensive pulmonary rehabilitation (PR) programs. ${ }^{6,7}$
Correspondence: Mandy Scheermesser Zurich University of Applied Sciences (ZHAW), School of Health Professions, Institute of Physiotherapy, Katharina-

Sulzer-Platz 9, P.O. Box, 840I.

Winterthur, Switzerland

Tel +4I 589346349

Fax +4I 589356349

Email mandy.scheermesser@zhaw.ch 
PA is defined as

Any bodily movement produced by skeletal muscles that result in energy expenditure above resting levels. PA broadly encompasses exercise, sports and physical activities done as part of daily living, occupation, leisure, and active transportation. ${ }^{8,9}$

Exercise is a subcategory of

PA that is planned, structured, and repetitive and [that] has as a final or intermediate objective the improvement or maintenance of one or more dimensions of physical fitness. ${ }^{8}$

Public health recommendations suggest that adults, including elderly or people with chronic conditions, perform at least 150 to 300 minutes of moderate-intensity or 75 to 150 minutes of vigorous-intensity aerobic physical activity a week and additional muscle strengthening activities involving major muscle groups on at least two days a week. ${ }^{10}$

PR programs that are aimed at enhancing exercise capacity and the promotion of an active lifestyle are the cornerstones of non-pharmacological COPD management. ${ }^{11,12}$ However, the PR induced improvement of physical performance and self-management skills do not lead to a higher level of PA in daily life in long-term perspective. ${ }^{7,13}$ The latest official position statement on PA in COPD by the European Respiratory Society, the following key component increase the effectiveness of behavioural interventions: mobilisation of social support, use of behaviour-changetechniques, assessment of readiness and motivation to change, provision of frequent contact time. ${ }^{14}$

However, changing PA behavior of individuals with COPD remains a challenge, since this population not only faces the same barriers to PA as the general population, but additional disease-specific barriers, such as dyspnea-related kinesiophobia. ${ }^{15-17}$ To increase PA for these individuals may be counterintuitive because this leads to an increase in their symptoms. However, a downward spiral of dyspnea-induced PA reduction could lead to changes in patients' lifestyles, which in turn would further lower activity levels and increase social isolation and depression. ${ }^{18}$ As a consequence, poor long-term participation in PA is common in individuals with COPD. ${ }^{19-21}$ As a remedy to this, the relevance of individualized PA counselling as part of PR has been emphasised in the literature. ${ }^{22,23}$ With the aim of influencing behavioral change over the long-term, PA counsellors provide support to patients in formulating and reaching their PA goals, reinforcing their COPD self-care skills, and helping them overcome their PA barriers. ${ }^{22}$ The use of Motivational Interviewing (MI) techniques for PA counselling has gained increasing recognition within the PR community. ${ }^{7,24}$

MI has been described as a "collaborative conversation style for strengthening a person's own motivation and commitment to change". ${ }^{25(\mathrm{p} 20)}$ It focuses on the exploration and evocation of a person's intrinsic motivation to change their perception towards a specific goal, eg daily PA. The therapist's aim is to detect a patient's ambivalence and to resolve it. This attitude is called "MI spirit" and is based on the four principles of collaboration, compassion, evocation and acceptance. ${ }^{25}$ The process of changing PA behavior can be divided into two phases - creation of the motivation to change and, subsequently, establishing a commitment to change. A non-judgemental and empathic communication style can help patients to make behavioral changes (eg quit smoking) ${ }^{26,27}$ or enhance treatment adherence. ${ }^{28}$ The Transtheoretical Model, which conceptualizes this process of behavioral change, assumes that individuals move through a series of stages (precontemplation, contemplation, preparation, action, maintenance, relapse) when changing their behavior. ${ }^{29}$ The time an individual remains in each stage may vary, and an individual may leave or re-enter at any stage.

Studies have indicated some positive effects on daily PA levels and daily steps, ${ }^{30}$ as well as on physical function, ${ }^{31}$ as a result of counselling using MI-techniques. However, the perceptions of change in PA, with a focus on motivation and coping strategies, comparing PR with and without PA counselling at different time periods (during and after PR) have not yet been investigated.

Therefore, the aim of this study was to differentiate types of patients based on their perception of PA and motivation for behavioral change in PA in daily life because of PR and counselling. Further, we explored to what extent counselling, when embedded in a PR program for individuals with COPD, influenced these aspects.

\section{Patients and Methods}

\section{Study Design}

This qualitative study was nested in a randomized controlled trial that primarily investigated the effect of counselling, as part of a comprehensive outpatient PR for individuals with COPD, on PA. ${ }^{32,33}$ The study was registered on the website of https://www.clinicaltrials.gov/ with the identifier NCT02455206 (27/05/2015), as well as on the Swiss National Trails Portal SNCTP000001426 (05/ 
21/2015). Qualitative methods were chosen to analyze and differentiate "types" of patients, based on perception of PA and motivation towards behavioral change in PA in daily life. This study adopted the criteria for qualitative research introduced by Flick und Steinke. ${ }^{34,35}$

\section{Ethical Considerations}

The study was approved by the local ethics committee (Canton of Zurich) on 4th May 2015 (PB_2016-01523) and this trial was conducted in accordance with the Declaration of Helsinki. Written informed consent was obtained from participants prior to baseline measurement.

\section{Participants}

From the total of 135 patients screened, 43 (32\%) were included in the trial and allocated to the intervention group (Physical Activity counselling Group), $(\mathrm{n}=17)$ and the usual care group ( $\mathrm{n}=26)$ (Figure 1). Participants had to fulfil the following inclusion criteria: age 40-90 years with confirmed COPD according to GOLD guidelines; ${ }^{18}$ German-speaking; planned participation in the PR program. Exclusion criteria were applied as previously described briefly summarized as mental or physical disability and severe uncontrolled co-morbidities. ${ }^{33}$

Of the 43 patients enrolled, 22 were invited to participate in the interviews, of whom four declined. The reasons for declining were "no consent to audiotaping", "lack of time", "no interest" and "forthcoming operation". Nine patients from the intervention group and nine patients from the control group were purposefully selected (gender, group allocation) (8 women, 10 men) and interviewed twice, at T1 after 12 weeks PR and at T2 after the threemonth follow-up. Ages varied between 50 and 86 years (median age 69), and GOLD COPD stages between 2 and 4 (Table 1).

\section{Intervention}

\section{Pulmonary Rehabilitation}

A comprehensive $\mathrm{PR}^{7}$ (named "PneumoReha") was performed, which included education and an individually tailored exercise intervention, according to the study protocol. ${ }^{33}$ For twelve weeks participants attended the outpatient clinic twice weekly (1.5-hour sessions) and received one session of supervised Nordic Walking training outdoors (1.5-hour session). Thus, a total of 36 physical training sessions were performed during the 12-week PR.

\section{Counselling Group}

Participants allocated to the intervention group received PR combined with counselling. The PA counselling was performed according to the principles of MI and imparted by two experienced physiotherapists, educated to Master of Science-level, who were not involved in the rehabilitation program. The study counsellors were trained in advance by an experienced MI-trainer (a member of the Motivational Interviewing Network of Trainers) and the

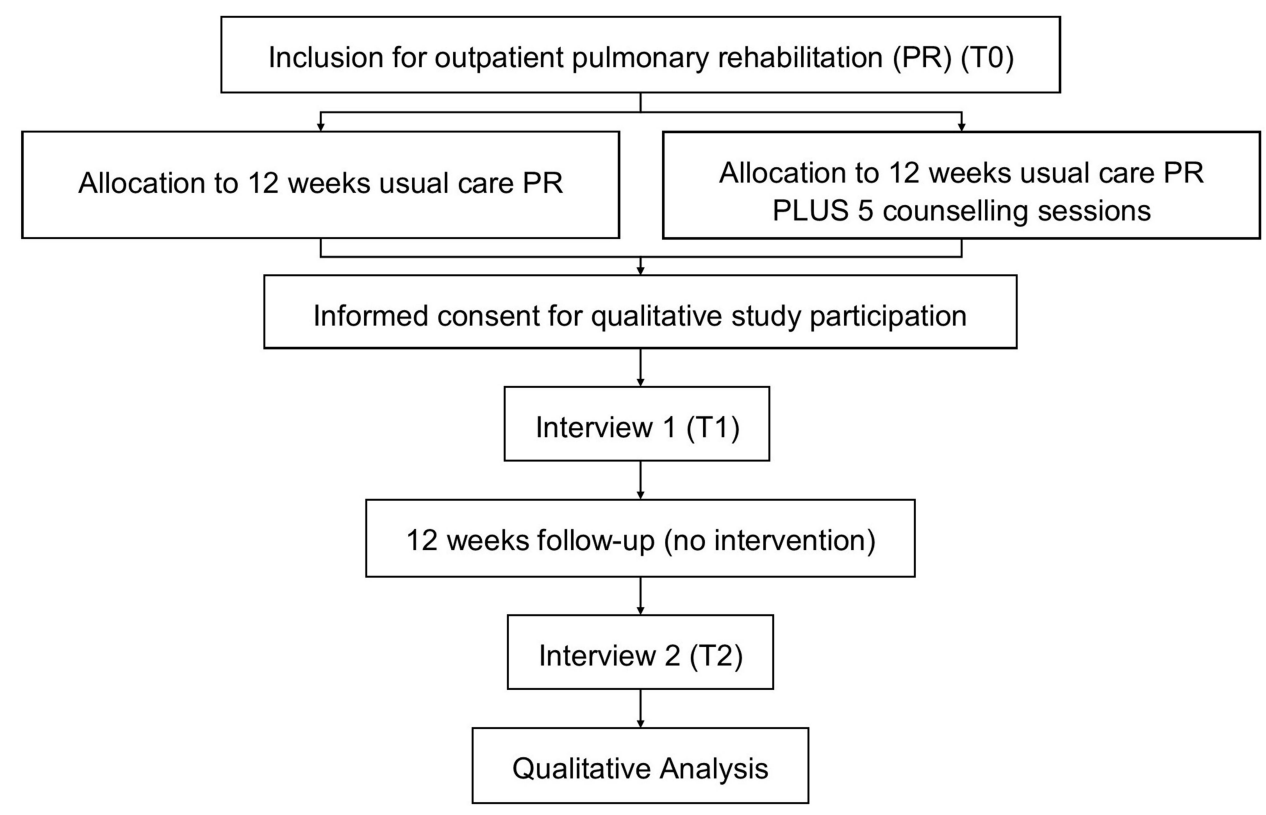

Figure I Flowchart of the study. 
Table I Overview of the Characteristics of the 18 Participants

\begin{tabular}{|l|l|l|l|l|}
\hline Number & Gender & Age & $\begin{array}{l}\text { GOLD- } \\
\text { Stage }\end{array}$ & $\begin{array}{l}\text { Counselling } \\
\text { Intervention Plus PR }\end{array}$ \\
\hline IDI6 & Male & 69 & 3 & Yes \\
ID38 & Male & 86 & 2 & Yes \\
ID34 & Male & 69 & 2 & Yes \\
ID46 & Male & 72 & 2 & Yes \\
ID72 & Male & 63 & 2 & Yes \\
ID7I & Female & 73 & 4 & Yes \\
IDIII & Female & 68 & 2 & Yes \\
IDI22 & Female & 64 & 3 & Yes \\
IDI24 & Female & 59 & 3 & Yes \\
ID29 & Male & 50 & 3 & No \\
ID6I & Male & 77 & 2 & No \\
ID82 & Male & 71 & 4 & No \\
ID85 & Male & 79 & 2 & No \\
ID77 & Female & 59 & 3 & No \\
ID25 & Female & 69 & 4 & No \\
ID22 & Male & 77 & 3 & No \\
IDI06 & Female & 66 & 3 & No \\
IDI26 & Female & 53 & 3 & No \\
\hline
\end{tabular}

Abbreviation: PR, pulmonary rehabilitation program.

quality of their performance assessed (Motivational Interviewing Treatment Integrity check MITI 4.1.2). ${ }^{36}$ During the twelve-week PR program, each individual allocated to the intervention group received five face-to-face counselling sessions, each lasting 30 minutes in duration. The PA stage of change assessment tool ${ }^{29,37}$ was used to tailor the counselling interventions to the individual.

\section{Control Group}

Participants allocated to the control group participated in the same PR but did not receive counselling sessions.

\section{Data Collection and Management}

The first author (MS) conducted a total of 36 semistructured interviews, of which 31 were conducted faceto-face at the rehabilitation facility, two at the patient's home and three held by telephone (due to Corona pandemic restrictions). The patients were informed in advance that the interviews would be audio-recorded and that any information referring to personal identity would be deleted from the transcripts. Each patient was interviewed twice, with the first interview being conducted after the twelve weeks of PR and the second after the three-month followup. The first interviews were 13 to 68 minutes in length and opened with the question, "Please describe how you experienced the pulmonary rehabilitation?" The interview guidelines focused on themes such as "personal experience of the PR", "daily activity and change in daily activity", "expectations", and "personal goals". The second interviews were 11 to 65 minutes in length and started with the opening question, "Please describe how you have been during the last three months?" These interview guidelines focused on the themes of "personal goals", "support in everyday life", and "daily activity". In both interviews, the patients in the intervention group were asked additional questions about the counselling (see Appendix 1). The Appendix 1 shows the detailed questions of the interview guideline.

Data collection was commenced in January 2016. Due to the Covid-19 pandemic, however, recruitment was halted in February 2020. The interviews were taped with a digital voice recorder and transcribed verbatim with the software f4. ${ }^{38}$ Data management and analysis were aided by the Atlas.ti 8 qualitative data analysis software.

\section{Data Analysis}

The first author (MS) and two other researchers (LR, AR) coded the transcripts of interviews independently. Firstly, case summaries were written for each case to obtain an overview of all interviews. Subsequently, the interview transcripts were coded for the thematic analysis. ${ }^{39}$ Thematic analysis involves familiarization with the textual data through repeated reading, identification of codes, and synthesis in larger thematic categories. The coding was guided by the interview guidelines, but inductive analysis of unanticipated topics or meanings was also considered. The various coding steps were performed by two researchers. A third researcher was consulted when agreement could not be reached. After the first coding, the initial codes were discussed. Following this, codes were combined to identify the main categories and sub-categories. The final coding system shows Appendix 2. The resulting list of codes was discussed with the clinicians (SB, DG, SR) to establish its plausibility and comprehensibility. The final coding system formed the basis for the analysis and the construction of the empirically derived "types". The aim was to analytically differentiate types of patients based on their perception of PA and motivation for behavioral change in PA in daily life because of PR and counselling. For this phase of the analysis, the group allocation to intervention or control was irrelevant. It is anticipated that the findings will contribute to a better understanding of patients' needs and enable the development of more targeted interventions, eg, in therapy and communication. ${ }^{40}$ The construction process can be divided into four stages. ${ }^{40,41}$ Stage 1: identification of relevant 
dimensions; Stage 2: grouping of cases and analysis of empirical regularities; Stage 3: analysis of meaningful relationships and type construction; Stage 4: characterization of types according to categories and dimensions.

In Stage 1, three categories were identified that comprehended the similarities and differences between types, according to the research question/study aim. ${ }^{41}$ The first category identified was "perceived PA behavior," ie, the ability to integrate PA into everyday life. This category reflected both the patient's perception of the intensity of PA (high, moderate, low, inactive, estimated using Metabolic Equivalent of Tasks, METs), ${ }^{42}$ as well as their perception of behavioral change in PA over time. The second category detected was that of "motivational quality" and focused on the reasons behind the motivation. Motivational quality ranges over a continuum from intrinsic motivation to extrinsic motivation. ${ }^{43,44}$ Intrinsic motivation is defined as "engaging in an activity for its own sake, because it is inherently enjoyable, satisfying or challenging". 45 ( $\mathrm{p} 2$ 2) Extrinsic motivation is characterized as

Engaging in behaviors for some separable outcome, whether this comes in the form of tangible rewards, social acceptance, proving something to oneself, or maintaining consistency between one's values and one's behaviors. ${ }^{45}$

The third category distinguished concerns the ability to apply coping strategies to overcome barriers and learn from crises, ${ }^{46}$ ie, yes or no. The development of "types" was conducted based on these three categories and their dimensions.
In Stage 2, the cases were grouped according to the three defined categories and dimensions. The cases assigned to a combination of characteristics were compared with each other to confirm the internal homogeneity of the constructed groups. To evaluate whether there was a sufficiently high external heterogeneity, the types were compared with each another. Finally, four types met the objectives of a typology, ie, high internal homogeneity within the type and high external heterogeneity compared with other types. ${ }^{41}$

In Stage 3, the meaningful relationships were analyzed to distinguish and characterize the different types.

In Stage 4, the four types were described according to their characteristics and the meaningful relationships. Each type was labeled according to their characteristics (Figure 2).

The code "MI", which included all statements regarding the intervention "counselling according to MI principles", was not included in the development of types, so that researchers were blinded to this characteristic $(50 \%$ of the patients). Finally, the distribution of the counselling intervention and usual care cases over the four types was analyzed.

\section{Results}

The results reflect an empirical development of patient types according to their perceived activity levels, coping strategies and motivational quality. Additionally, the distribution of cases across the groups intervention and control within this typology are represented. The different types developed in this study used Weber's approach to Ideal Types, ${ }^{47}$ meaning that they were derived from, but

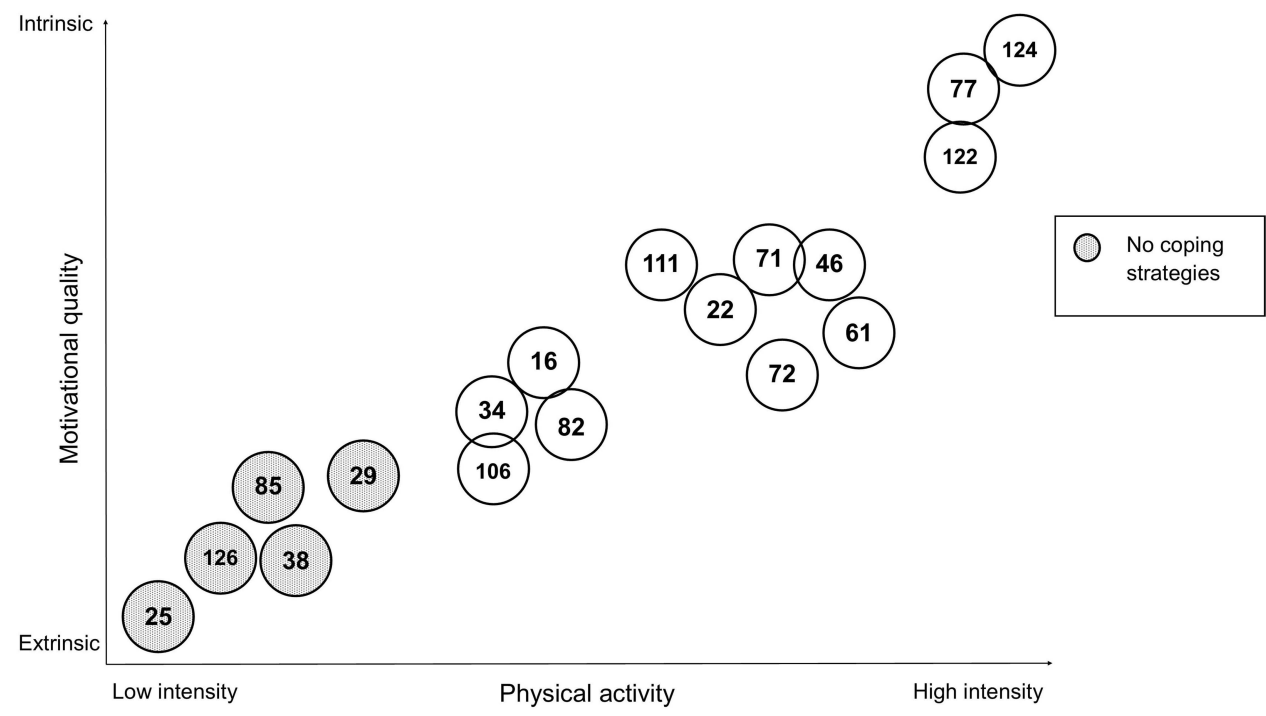

Figure 2 Development of types. Each participant is represented by a circle with their corresponding ID-number. Participants were grouped according to motivational quality (continuum from extrinsic to intrinsic) and PA (continuum from low intensity to high intensity). 
not representative of, social reality. Instead, ideal types are analytical constructs with distinct explanatory characteristics that enable comparison within and across types. This is important to note because it means that individuals with COPD could be categorized into several, or all, of the types over time.

\section{Type I: High Activity Level and High Intrinsic Motivation}

The first type is characterized by self-perceived high activity levels and motivational quality that tends to be intrinsic. Type 1 has acquired strategies to cope with barriers and to maintain activity levels and motivation, even though personal crises. Individuals of this type perform a variety of activities or sports, eg, walking, climbing stairs, cycling, home exercise and yoga. All Type 1 individuals perceived improvements in their level of fitness and physical function over the course of the rehabilitation program and reported a more active lifestyle after the end of the intervention.

The PneumoReha program educated patients to acquire knowledge of the body and its functions ("The heart is a muscle" ID124). This strengthened patients' trust in their bodies and capabilities and helped them to overcome their fears. Type 1 individuals learned how to push their boundaries and how to apply new strategies in their daily lives.

\footnotetext{
"Things are not like they used to be. I used to be afraid of a cold; I used to be afraid of everything. I was able to lose my fears. I have never experienced cardiac chest pain again. That only occurred the first couple of times. Following that, it stopped. Today, I also do not experience any palpitations anymore, which used to make me think, today I had a very exhausting day. Even less so. And no one has ever told me that before/I am grateful for what I have learned". (ID124)
}

The newly acquired knowledge, the (regained) confidence in their physical abilities, combined with positive outcome experiences, are the motivating factors for Type 1 patients not to fall back into their pre-rehabilitation state. They are highly motivated to preserve the progress they have made. The motivational quality of Type 1 individuals can be described as integrated and/or intrinsic. Persons of Type 1 are proud of what they have achieved, they are less fearful, they feel strong, and find enjoyment in the act of moving and exercising itself. Close social contacts (such as grandchildren, partner, or friends) and objective data on their exercise progress (such as digital step counts) are also factors that support their motivation. Additionally, Type 1 individuals report psychological benefits of exercise, "It also improved my self-esteem. It helps to feel like things are possible again. It increases your personal feeling of self-worth." (ID7). Type 1 patients experience internalized extrinsic motivation: for example, they personally believe that regular PA is consistent with their value of personal health and, thus, is an important goal to accomplish.

Over the course of the PR program, Type 1 persons learned and developed their own strategies to react to difficult situations and overcome obstacles, while trying to maintain their PA levels. Example of these strategies are mindfulness and breathing exercises, and also setting themselves realistic daily goals - as one patient reported:

\section{"(...) if you experience that shortness of breath, you get a bit panicky. In addition, they [the therapists] were able to resolve that panic. By motivating me to keep going any- way. By breathing together with me and showing me, that it is possible to reach one's goal despite the exertion (...). That benefited me greatly. (...) and I could also implement it at home, (...) I have more self-confidence and I know that, if I am not feeling well, if I experience troubles with breathing, I can help myself. (ID77)}

Even personal crises, such as a cancer diagnosis, surgery, or exacerbation, did not demotivate (discourage) patients of this type from keeping physically active. Instead, they maintained their training routines to the greatest extent possible and worked towards rebuilding their former fitness levels.

\section{Type 2: Moderate Activity Level and a Mixture of Intrinsic and Extrinsic Motivation}

The second type displays both intrinsic and extrinsic motivational quality combined with a moderate level of activity, these activities being predominantly embedded in everyday life and the household. Type 2 persons usually have knowledge of possible coping strategies to overcome obstacles, even if they do not always apply them ("I just have to give myself a push every time so that I do something extra" ID46).

Over the course of the PR program, Type 2 individuals felt that they were able to improve their fitness levels («less difficulty breathing than before»ID71) and change their attitudes toward PA. For example, they see it as important to exercise regularly and they try to implement 
regular exercise, according to their opportunities. The implemented changes appeared to be slightly less than those of Type 1 . The activities continued by Type 2 after rehabilitation were either part of a targeted training (eg, Theraband exercises), or, to a larger extent, activities embedded in everyday life (eg, climbing stairs, going for a walk) and the household (eg, gardening, shopping).

(...) so certainly something has changed. I mean I have never been the athletic type. But now at least sometimes I pull myself together for some Theraband exercises, I do a lot and yes a little bit of walking I have to do anyway. (ID72)

The motivational quality of Type 2 persons can be described as presenting both extrinsic and intrinsic components. Strong incentives for this type of individual are external factors, such as social support (eg, from the family) and the purpose and outcome of the activity (eg, keeping the garden in good shape, providing for the wife in need of care). The PR program plays an important role in motivating individuals of this type: participation in the program imposes a fixed exercise routine and can contribute to motivation through the social aspects of the peer group. Through the PneumoReha program, patients rediscovered pleasure in activities such as walking («it's actually also fun for me» ID72) and developed a positive attitude towards exercise: it is good for you and can slow the progression of the disease.

After all, I can't just sit in the chair and wait until it gets better again or. It is not going to get better. However, if I do something, then it gets better. And otherwise it just does not. (ID61)

Compared to Type 1 individuals, the intrinsic component is clearly less pronounced in Type 2 patients. However, for some patients, there was an indication that intrinsic motivation was supported by the PR program, especially in those patients who did not see themselves as «the athletic type» (ID72). «[In the] past [I] always had a convenient excuse (...). Now I do not have that anymore.» (ID46)

Type 2 individuals have a reflective attitude to barriers and difficulties that they encounter and are mostly aware of strategies to deal with them. They described personal factors («my basic attitude is rather sluggish» (ID46)) or external environmental factors (eg, bad weather) as barriers. Strategies to overcome external barriers include adjusting the daily schedule, eg, doing household activities instead of going outside for a walk, or doing a shorter walk. Unlike Type 1 individuals, Type 2 did not describe specific strategies for dealing with «internal» barriers, such as their attitude or personal fears.

Exacerbations, which can occur periodically in COPD, were viewed in a realistic light. Patients were not demotivated by a worsening health status, but learned to cope with it and found their own ways of dealing with the situation.

Of course, I have already lowered my performance today. I realized today, I can't do it anymore, uh couldn't keep up with my last performances, I had to cut back everything a bit, but of course I hope, because I've now skipped half a year [of training], that I can then successively increase again, that I will get back to where I was before. That will be difficult, but if I then train rigorously, and still do a bit at home, a bit of training. To be back on track again at some point. ID22)

\section{Type 3: Low to Moderate Activity Level and Extrinsic Motivation with Coping Strategies}

The third type is characterized by a low to moderate activity level in everyday life. From the perspective of Type 3 individuals, the regular participation in the PR program sessions is a satisfactory amount of PA. Most patients know coping strategies that help them deal with obstacles and they are successful in implementing them. The motivation for PA is predominantly extrinsic and purpose bound.

Persons of this type see a clear benefit of participating in the PR and/or its follow-up program. They reported that their physical performance was measurably improved by participation in the program: «I have more or less doubled my performance on the training devices since the start of the program and also on the exercise cycle, I would say more or less doubled now, but that is good, the result was very good" (ID82).

Compared to their physical capacity prior to participating in the PneumoReha program, Type 3 persons perceived positive changes in their physical constitution. This can be seen in descriptions of increased performance regarding general endurance, or easier completion of activities in daily life, such as household tasks, or grocery shopping. Patients reported that «it could also be the case that the wife has something on the agenda, then I (...) go shopping myself» (ID16) and that light endurance activities, such as climbing stairs or going for a walk, became easier («it is 
a little better with climbing stairs, it is a little better with carrying bags» (ID82); «I mean, today climbing stairs and so on, that is possible again (.) Perfectly. «ID16).

Along with self-perceived improvements in physical function, small, but nevertheless important, changes in PA behavior were described by Type 3 individuals. They reported "taking the bus, (...) and getting off one stop early to walk to the next stop." (ID106), or "go to town by bike more often, in the past I used to take the bus", or "not using the elevator" (ID34). Overall, they see their regular participation in the program sessions as a great success and as a sufficient amount of training. «It would be better to walk half an hour every day, but I am too lazy (...). I think, if I did not always participate in PneumoReha, or if I had not participated last time, I think my health would not be as good as it is today" (ID111).

Patients of this type have developed strategies to overcome barriers and they use them in everyday life, for example, relying on support from their social network ("the wife and the children, they say, you have to do something now. And now it's better]" (ID61), reducing the intensity of training in case of an exacerbation ("I went despite the exacerbation, and I just reduced, but I kept going" (ID34)), and sitting tight and waiting it out ("just persevere" (ID106)).

Persons of this type are mainly motivated by extrinsic aspects. Their focus is on the preservation of their physical function («I do not need [a] performance record that I did 20,000 steps today or so, but uh the goal is just that I can keep the level.» ID34) against the backdrop of the possible consequences of the disease («and once you have THAT [COPD], then (...) all you can actually do is just to keep the progression stable or slow it down» ID16). Other important motivating factors are shared experiences and activities with others, eg, playing soccer with grandchildren, model flying with colleagues, or traveling with spouse or friends.

\section{Type 4: Low Activity Level and Quality of Motivation with No Coping Strategies}

Type 4 is characterized by a lower activity level than Type 3. Similarly, participation in the PR program is the most meaningful change in PA for these patients. The motivational quality of Type 4 is mainly extrinsic, ie, through external influences and obligations, and intrinsic motivation is low to non-existent.
Over the course of the PneumoReha program, most Type 4 patients reported that they were able to improve their physical capacity ("It was measurable with the training cycle. Each time I increased the performance." ID38). In some cases, daily life activity was increased due to the program. One patient reported how the program prompted him to be more active - he had discovered e-biking together with his wife: «Yes, I have now, (...) my wife bought an electric bike and then she said come and take mine, I will follow you on the racing bike and then we (...) went out together (...)» (ID85).

However, PA of Type 4 is mainly limited to the PneumoReha program and, other than engaging in the program sessions, these patients adhere to the activities that they carried out previously. These include walking, leisure activities with a low activity level, such as shopping or going to a café, and household activities.

The motivational quality of Type 4 is predominantly extrinsic. Motivating factors are obligations and regular errands that must be completed, such as walking the dog. Additionally, they are influenced by others, such as their pulmonary physician or their spouse, «Because the doctor is always pestering me about it" (ID25). Another strong motivator is the possible negative consequences of inactivity in COPD, of which the affected are well aware.

MOTIVATED? (laughs) What can I say .... I KNOW that I HAVE to. I have to stay ACTIVE. If I sit around, soon it will be over. That's how it is. No no, that is quite CLEAR. You snooze, you rust. And that is quite EXTREME with the disease. (ID29)

I have a sister who is on oxygen treatment. She's in a nursing home, and she's not doing so well. And I think (...) I don't want that yet. (ID126)

Furthermore, Type 4 individuals are characterized by having fewer, or less clearly described, coping strategies. The barriers to PA for Type 4 individuals are similar to those of the other types - environmental factors, such as the weather, and health problems, such as exacerbations or pain («And have skipped it (the training) now though, because it just does not work, I cannot, (...) the pain is too much» (ID85). Despite these perceived obstacles, patients still make an effort to persevere, especially with regard to participation in the PneumoReha program. However, they are less likely to describe concrete strategies and tend to adopt a more passive attitude in dealing with obstacles and crises, «No. That would then be like suffocating, so exhausted. Simply exhausted. 
Just not being able to do it anymore, it's not even because of the difficulties with breathing, you are just down.» (ID38).

Figure 3 shows that patients with a allocation to the intervention group mainly fell into the Types 1 and 2 . These categories are characterized by either high intrinsic motivation or a mixture of intrinsic and extrinsic motivation. Similarly, high to moderate activity levels are perceived in the Type 1 and Type 2 categories. This is quite different to Types 3 and 4, which included more individuals from the control group allocation and which are characterized by a lower activity level, almost no or no coping strategies, and extrinsic or no motivation.

\section{Impressions of Counselling Based on MI-Techniques}

Individuals who received counselling generally had a positive attitude towards it. They appreciated the atmosphere of the conversations and described the physiotherapists conducting the MI-sessions as likeable, ("If I am being honest, I was always looking forward to the interview with her" ID46). The individuals of Types 1 and 2 who received counselling were distinctively outspoken about their impressions of counselling and the effects it had on them. They described how it supported their selfefficacy, which is a central goal of this technique,

"This made a real difference. I could really tell her things. My friends are not interested whether I can do 400 or $490 \mathrm{~m}$. (...) I was so proud, and I could tell her all those things and I think that's great. It's sad, that there aren't more people participating in the study, they will never know how motivating these conversations can be. It was like a motivational talk." (ID111)

"It really helped. I have been writing a diary over the course of the PR. (...) and it is astonishing to see, the first months were full of worries, where is this taking me, isn't this too much etc. And suddenly that changed. Suddenly, there were goals, this is where I want to be. I can do it. I can reach these goals. With these interviews, above all with these interviews". (ID124)

Some individuals of Type 3 described their perception and benefits of counselling as being less satisfactory:

"Originally, I was there to train, not to talk. There might be individuals needing this, someone who is in a depression (.)” (ID16)

"What am I doing, why and why did I get to this point where I am now? I was able to talk about that (.) in a relaxed conversation. (.). But I don't think you have to integrate it into the program. I don't believe in the success of such a program.” (ID 34)

The quote, "It is assumed that the healthy body itself mobilizes resistance to get back on its feet." (ID38) represents the passive and non-responsive attitude towards counselling of Type 4 individuals. Furthermore, this individual is disappointed with the PneumoReha and counselling because, despite measurable changes in their exercise capacity, only very small improvements in activities of everyday life were felt. «If you look at what you did at the beginning of the

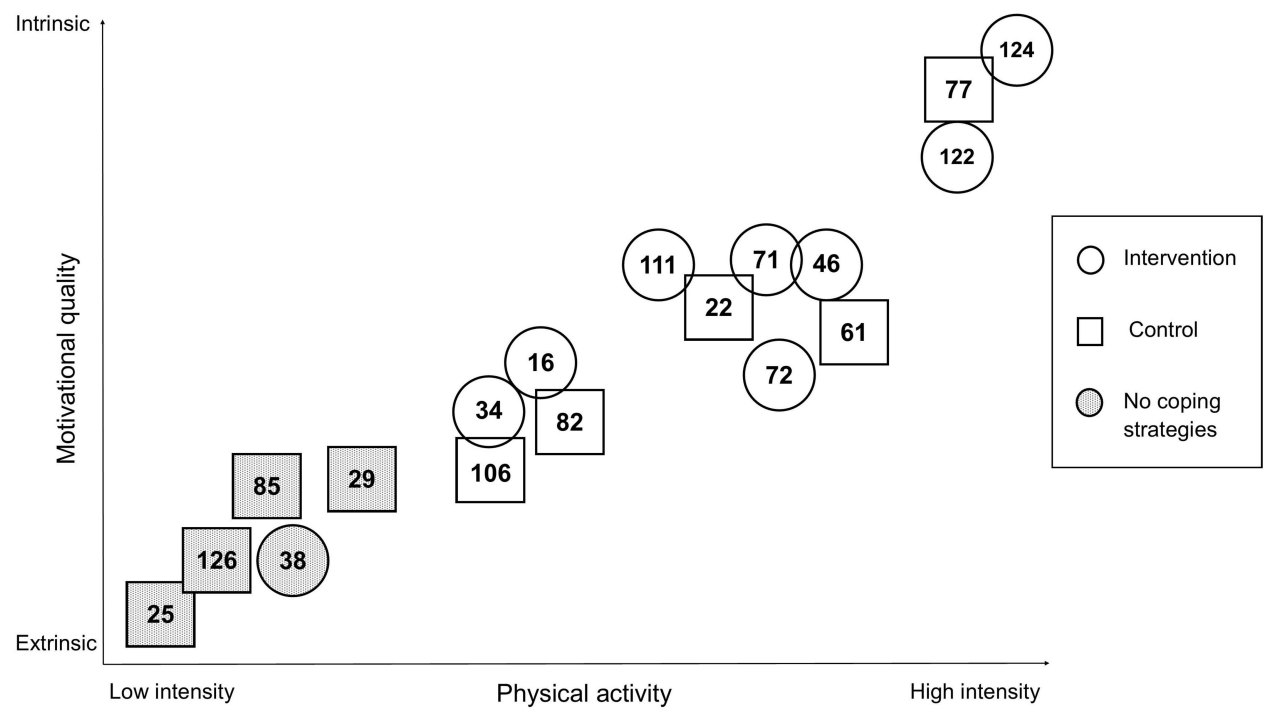

Figure 3 Distribution of participants by study group (Intervention=counselling intervention group, Control=control group) and ID-number, according to motivational quality and PA intensity. 
PneumoReha and how it looks now at the end, there are clearly increases. (...) From that point of view, it has already made a difference. But it is also measurable. But for me (...) in daily life (...) I do not know.» (ID38) He concludes, «It does not help and it does not harm.» (ID38)

\section{Discussion}

Four different types of individuals with COPD were constructed based on the three characteristics "perception of PA intensity and changes in PA behavior", "quality of motivation to perform PA" and "strategies to overcome barriers". The descriptive results show that individuals who participated in combined counselling and PR tended to be more active and had higher intrinsic motivation. The typology can be used to better understand how to support people with COPD to stay active. It can also inform the development of more effective, tailored interventions.

While our findings suggest that counselling based on MI-techniques may have supported individuals with COPD in moving towards more autonomous PA behavior, those patients assigned to the intervention group assessed the value of the counselling heterogeneously. Some disliked the additional appointments for "only talking, not exercising", while others saw great benefit in the individual counselling. Type 1 individuals who experienced the counselling sessions as very positive and supportive, appeared to be the most motivated and active participants. It cannot be said whether these persons were already open to change and that the counselling was simply the intervention they needed to initiate a PA behavioral change, or, whether the counselling intervention itself initiated the change in attitude and perceptions regarding PA in their daily lives. Individuals of this type are in the "action" or "maintenance" stage of change, 29 meaning that the anticipated health benefits and/or their personal intrinsic needs convinced them to be active. Type 1 persons need support to initiate specific actions or to maintain regular PA. Counselling is focused on the application of strategies to cope with barriers that hamper planned PA behavior, such as goal setting, action planning, or developing strategies. ${ }^{48}$ However, differences in the perceptions of counselling intervention and the willingness to engage were revealed in this study. In Type 1 individuals, the interaction between patients, rehabilitation, and counselling became clear. This is shown by the observation that counselling seemed to work particularly well for those patients who were able to optimally combine their (body) knowledge and coping skills learned during rehabilitation with the motivation gained during the counselling sessions. The result was a regained trust in their body and in their abilities, as well as an increase in PA. Type 1 individuals need regular support in the evaluation of exercise modalities and goals, but this does not necessarily have to take place in a PR setting. Regular counselling sessions and peer support (eg, group exercise training) might be sufficient. These highly active individuals with COPD were previously called "busy bees" and account for about $2 \%$ of COPD patients. ${ }^{49}$

Type 2 individuals see the benefits of regular PA and are engaged in household activities and daily routines (eg, using the stairs instead of the elevator). However, their motivation to engage in PA is guided by the aim to achieve fitness improvements additional to PR, rather than finding enjoyment in PA itself. Individuals are in the "action" phase according to the stage of change model. ${ }^{24}$ Counselling may focus on relapse prevention and reinforcing the patient's PA behavior. Social support is a strong motivating factor for this type. Therefore, reference persons, eg, wife or grandchild, could participate in counselling sessions to fine-tune PA goals, action plans and coping strategies, according to personal preferences.

The PA behavior of Type 3 individuals was changed by PR participation and relapse to earlier stages of change needs to be avoided. Accordingly, counselling session could focus on increasing the active time spent on light activities and the reduction of sedentary behavior, with a consequent decrease in the risk of hospitalization due to COPD. ${ }^{50}$ Continuous behavioral change interventions, based on goal-setting and self-monitoring, might help to maintain active behavior.

Type 4 individuals described a more sedentary lifestyle and match the previously described typology of "couch potatoes". 49 They are characterized by more time spent on light PA intensity and less time in moderate-to-vigorous intensity. However, based on the findings from our study, in some cases this may be linked to individual hardship, for example, psychological problems. This could be a reason as to why these participants seemed less, or not at all, responsive to change initiated by PR and/or counselling. This finding supports evidence that patients with greater baseline PA levels benefit more from PA promotion. ${ }^{51}$ Individuals of this type recognize that inactive behavior has negative health consequences, and this is the reason that they decide to participate in PR. However, it is unclear whether the individuals in this group are less aware of the fact that participating in PR once a year may not be sufficient to maintain consistent health benefits. A personal lifestyle change appears to be difficult to achieve because individuals feel ambivalent about change. 
Counselling interventions in the stages of precontemplation, contemplation, and preparation could focus on raising consciousness and facilitating the behavioral change process. ${ }^{29}$ Type 4 individuals are those that may benefit most from regular participation in PR. ${ }^{49}$

Results show that participants of all types appreciated the physical benefits of PR and that they were able to improve their physical capacity. The main difference between types can be pinpointed to their respective concept of PA and what "physical activity" means to them. When patients were asked to describe their activities, they often reported household chores and activities to maintain their independence/autonomy, eg, transport/car, having hobbies, playing with grandchildren (see Types 3 and 4). From the patient's perspective, being active is often understood more broadly than "just" performing physical exercise. This focus on daily life activities seems to be common in individuals with COPD, irrespective of country or disease characteristics. ${ }^{52}$ Types 1 and 2 tend to differentiate between daily life activities and planned, structured exercising in order to improve or maintain fitness. Therefore, further research needs to explore patients' concepts of PA according to their typology, to be able to provide rehabilitation programs that better correspond to the mindsets of patients.

Another aspect of combined counselling and PR was its contribution to establishing a lasting PA routine for individuals of Types 1 to 3. Participants reported that they had established new exercise routines, or found new activities, that they were determined to adhere to in the future. This long-term intention to change PA behavior indicates a positive effect of combined counselling and PR on the motivation of participants to continue with their PA routine. However, the quantitative results from the trial did not show any significant effect on PA behavior (mean steps, MET) after 6 months, for either PR or combined counselling and PR. ${ }^{23,32}$ This discrepancy between qualitative and quantitative findings has been reported in previous studies on PR including MI-counselling. ${ }^{53}$

The authors propose to focus future research on the identification of individuals with the potential to respond positively (eg, according to confidence level and readiness to change), on the development of more tailored counselling interventions, and on the optimization of the timing of the intervention delivery (eg, rather than delivery during early PR, delivery at the end of PR, or during the transition to the daily routine phase). Evidence shows that individuals with COPD are less active directly after PR (need to recover) but may increase their levels of PA again following this period. ${ }^{54}$ During this later period, external support might well be useful. In this respect, the growing volume of knowledge on barriers and facilitators to PA in individuals with $\mathrm{COPD}^{15,17}$ and behavioral change techniques ${ }^{55}$ may be useful. Future studies are needed to investigate whether counselling, when embedded in a PR program, can help to change patients' daily PA behavior, and to identify which individuals benefit the most.

\section{Limitations}

Although saturation of themes was achieved in this sample, the study also has several limitations. The interviews were guided by a semi-structured interview guide, which enhanced the dependability of the study. Face-to-face interviews were well suited to the purpose because they allowed personal contact between the interviewer and the patient. Telephone interviews, however, were less suitable but deemed necessary due to Covid-19 restrictions. The first author was experienced in conducting and analyzing interviews, and there was continual discussion between all authors during the analysis process to reach consensus, which further strengthened the dependability of the trial.

Interviews were conducted directly following the PneumoReha program and at the three-month follow-up. An additional interview at the start of the program would have been useful to better understand the course of the interventions over time. Additionally, the period of three months after PR was too short for the evaluation of longterm behavioral changes. Despite these limitations, this study might be a useful starting point for further research, since it is the first to develop types of COPD patients according to perceived PA, quality of motivation, and coping behavior.

\section{Conclusion}

A typology of four types of people with COPD was developed, characterized by their perception of activity, individual motivation and strategies for managing barriers. The patients' physical activity level might be influenced by their concept of physical activity and the quality of motivation. Recognizing patients' different activity behaviors is important for improving the quality of outpatient PR programs and developing tailored (according to each type) counselling interventions embedded in outpatient PR programs.

\section{Abbreviations}

COPD, Chronic Obstructive Pulmonary Disease; ID, Identification number in Atlas.ti; KSW, Kantonsspital Winterthur, Cantonal Hospital Winterthur; METs, Metabolic Equivalent of Tasks; MI, Motivational 
Interviewing; MITI, Motivational Interviewing Treatment Integrity; YPA, physical activity; PR, pulmonary rehabilitation; ZHAW, Zurich University of Applied Sciences.

\section{Data Sharing Statement}

The raw data (interview transcripts) that support the findings of this study are available from the corresponding author (MS) (email: mandy.scheermesser@zhaw.ch) upon reasonable request. The data are not publicly available due to information shared in the interviews that could compromise the privacy of research participants.

\section{Ethics Approval and Consent to Participate}

The study was approved by the regional ethics committee (Canton of Zurich) on 4th May 2015 (PB_2016-01523). Written informed consent was obtained prior to interviews.

\section{Acknowledgments}

The researchers are grateful to Christa Wachter for her considerable support and assistance in collecting and processing the data. Many thanks to the students at the ZHAW for the transcription of the audio files, and to the Institute of Physiotherapy team at the Cantonal Hospital Winterthur (KSW) for its support. The authors would like to express special thanks to all participants and their relatives who kindly took part in this study.

\section{Author Contributions}

MS, MW and AR were responsible for the conception of the project. MS conducted all interviews. MS, LR and AR performed the data analysis, interpreted the results, and drafted the manuscript. DG, SB, SR and TH supported the interpretation of results. All authors made substantial contributions to conception and design, acquisition of data, or analysis and interpretation of data; took part in drafting the article or revising it critically for important intellectual content; agreed to submit to the current journal; gave final approval of the version to be published; and agree to be accountable for all aspects of the work.

\section{Funding}

This study was supported by the Swiss Lung Association. Funding included the cost of devices (accelerometer) and some working hours.

\section{Disclosure}

All authors declare that they have no competing interests.

\section{References}

1. Troosters T, Sciurba F, Battaglia S, et al. Physical inactivity in patients with COPD, a controlled multi-center pilot-study. Respir Med. 2010;104(7):1005-1011. doi:10.1016/j.rmed.2010. 01.012

2. Garcia-Aymerich J, Lange P, Benet M, Schnohr P, Anto JM. Regular physical activity reduces hospital admission and mortality in chronic obstructive pulmonary disease: a population based cohort study. Thorax. 2006;61(9):772-778. doi:10.1136/thx.2006.060145

3. Garcia-Aymerich J, Farrero E, Felez MA, et al. Risk factors of readmission to hospital for a COPD exacerbation: a prospective study. Thorax. 2003;58(2):100-105. doi:10.1136/thorax.58.2.100

4. Pitta F, Troosters T, Probst VS, Spruit MA, Decramer M, Gosselink R. Physical activity and hospitalization for exacerbation of COPD. Chest. 2006;129(3):536-544. doi:10.1378/chest.129.3. 536

5. Waschki B, Kirsten A, Holz O, et al. Physical activity is the strongest predictor of all-cause mortality in patients with COPD: a prospective cohort study. Chest. 2011;140(2):331-342. doi:10.1378/chest.10-2521

6. Nici L, Donner C, Wouters E, et al. American Thoracic Society/ European Respiratory Society statement on pulmonary rehabilitation. Am J Respir Crit Care Med. 2006;173(12): 1390-1413. doi:10.1164/rccm.200508-1211ST

7. Spruit MA, Pitta F, McAuley E, ZuWallack RL, Nici L. Pulmonary rehabilitation and physical activity in patients with chronic obstructive pulmonary disease. Am J Respir Crit Care Med. 2015;192 (8):924-933. doi:10.1164/rccm.201505-0929CI

8. Caspersen CJ, Powell KE, Christenson GM. Physical activity, exercise, and physical fitness: definitions and distinctions for health-related research. Public Health Rep. 1985;100(2):126-131.

9. Garber CE, Blissmer B, Deschenes MR, et al. American college of sports medicine position stand. Quantity and quality of exercise for developing and maintaining cardiorespiratory, musculoskeletal, and neuromotor fitness in apparently healthy adults: guidance for prescribing exercise. Med Sci Sports Exerc. 2011;43(7):1334-1359. doi:10.1249/MSS.0b013e318213fefb

10. World Health Organisation. WHO guidelines on physical activity and sedentary behaviour; 2020.

11. Lopez-Campos JL, Soler-Cataluna JJ, Miravitlles M. Global strategy for the diagnosis, management, and prevention of chronic obstructive lung disease 2019 report: future challenges. Arch Bronconeumol. 2020;56(2):65-67. doi:10.1016/j.arbres.2019.06.001

12. Society ER. Pulmonary rehabilitation; 2020. Available from: https://www. erswhitebook.org/chapters/pulmonary-rehabilitation/. Accessed July 26, 2021.

13. Waschki B, Kirsten AM, Holz O, et al. Disease progression and changes in physical activity in patients with chronic obstructive pulmonary disease. Am J Respir Crit Care Med. 2015;192 (3):295-306. doi:10.1164/rccm.201501-0081OC

14. Watz H, Pitta F, Rochester CL, et al. An official european respiratory society statement on physical activity in COPD. Eur Respir J. 2014;44(6):1521-1537. doi:10.1183/09031936.00046814

15. Thorpe O, Johnston K, Kumar S. Barriers and enablers to physical activity participation in patients with COPD: a systematic review. J Cardiopulm Rehabil Prev. 2012;32(6):359-369. doi:10.1097/ HCR.0b013e318262d7df

16. Gürses, H. N., Saka, S., Uçgun, H., Zeren, M., \& Bayram, M. Obstacle of physical activity and activities of daily living in patients with COPD: dyspnea related kinesiophobia. Eur Respir J. 2019;54. doi:10.1183/13993003.congress-2019.PA1247 
17. Robinson H, Williams V, Curtis F, Bridle C, Jones AW. Facilitators and barriers to physical activity following pulmonary rehabilitation in COPD: a systematic review of qualitative studies. NPJ Prim Care Respir Med. 2018;28(1):19. doi:10.1038/s41533-018-0085-7

18. Vestbo J, Hurd SS, Agusti AG, et al. Global strategy for the diagnosis, management, and prevention of chronic obstructive pulmonary disease: GOLD executive summary. Am J Respir Crit Care Med. 2013;187(4):347-365. doi:10.1164/rccm.201204-0596PP

19. Lima F, Altero G, Franco MC, et al. Factors influencing participation and adherence to a pulmonary rehabilitation program in patients with COPD: a qualitative study. Eur Respir J. 2016:48.

20. Guo SE, Bruce A. Improving understanding of and adherence to pulmonary rehabilitation in patients with COPD: a qualitative inquiry of patient and health professional perspectives. PLoS One. 2014;9 (10):ARTN e110835. doi:10.1371/journal.pone.0110835

21. Hayton C, Clark A, Olive S, et al. Barriers to pulmonary rehabilitation: characteristics that predict patient attendance and adherence. Respir Med. 2013;107(3):401-407. doi:10.1016/j.rmed.2012.11.016

22. Pitta F, Burtin C. Erratum to: the physical activity coach in pulmonary rehabilitation. In: Clini EM, Holland AE, Pitta F, Troosters T, editors. Textbook of Pulmonary Rehabilitation. Cham: Springer; 2017:E1-E1.

23. Burge AT, Cox NS, Abramson MJ, Holland AE. Interventions for promoting physical activity in people with chronic obstructive pulmonary disease (COPD). Cochrane Database Syst Rev. 2020;4: CD012626. doi:10.1002/14651858.CD012626.pub2

24. Excellence NIfHaC. Self-management interventions, education and telehealth monitoring. IN: chronic obstructive pulmonary disease in over 16s: diagnosis and management. NICE Guideline No.115. NICE; 2019.

25. Miller WR, Rollnick S. Motivational Interviewing. Preparing People to Change. 3rd ed. The Guildford Press; 2013.

26. Zidarn M, Kolenko A. Effectiveness of motivational interview for smoking cessation in hospital setting. Eur Respir J. 2016;48:PA4310. doi:10.1183/13993003.congress-2016.PA4310

27. Efraimsson EO, Fossum B, Ehrenberg A, Larsson K, Klang B. Use of motivational interviewing in smoking cessation at nurse-led chronic obstructive pulmonary disease clinics. $J$ Adv Nurs. 2012;68 (4):767-782. doi:10.1111/j.1365-2648.2011.05766.x

28. Naderloo H, Vafadar Z, Eslaminejad A, Ebadi A. Effects of motivational interviewing on treatment adherence among patients with chronic obstructive pulmonary disease: a randomized controlled clinical trial. Tanaffos. 2018;17(4):241-249.

29. Prochaska JO, Velicer WF. The transtheoretical model of health behavior change. Am $J$ Health Promot. 1997;12(1):38-48. doi:10.4278/0890-1171-12.1.38

30. Lahham A, McDonald CF, Holland AE. Exercise training alone or with the addition of activity counseling improves physical activity levels in COPD: a systematic review and meta-analysis of randomized controlled trials. Int $J$ Chron Obstruct Pulmon Dis. 2016;11:3121-3136. doi:10.2147/COPD.S121263

31. Benzo R, Vickers K, Novotny PJ, et al. Health coaching and chronic obstructive pulmonary disease rehospitalization. a randomized study. Am J Respir Crit Care Med. 2016;194(6):672-680. doi:10.1164/ rccm.201512-2503OC

32. Rausch AK, Beyer S, Gisi D, et al. Effect of counselling during pulmonary rehabilitation on self-determined motivation to be physically active for people with chronic obstructive pulmonary disease a pragmatic RCT. BMC Pulmonary Med. 2021;17:1-9.

33. Rausch-Osthoff AK, Greco N, Schwank A, et al. Effect of counselling during pulmonary rehabilitation on self-determined motivation towards physical activity in people with chronic obstructive pulmonary disease - protocol of a mixed methods study. BMC Pulm Med. 2017;17(1):115. doi:10.1186/s12890-017-0457-8

34. Flick U. Managing the Quality of Qualitative Research. Sage; 2008.
35. Steinke I. Kriterien qualitativer Forschung. Ansätze zur Bewertung qualitativ-empirischer Sozialforschung. [Criteria of qualitative research. Approaches to the evaluation of qualitative-empirical social research]. Juventa; 1999. German.

36. Moyers TB, Manuel JK, Ernst D. The German Version of the motivational interviewing treatment integrity coding manual 4.2.1 (MITI 4.2.1) unpublished manual, German version. Available from: https:// casaa.unm.edu/download/miti_german.pdf2014. Accessed August 11, 2021.

37. Rausch AK. Physical activity stage of change assessment tool - german version. Zurich University of Applied Sciences; 2017. Available from: https://digitalcollection.zhaw.ch/handle/11475/1231. Accessed July 26, 2021.

38. Dresing T, Pehl T. Praxisbuch interview, transkription \& analyse. anleitungen und regelsysteme für qualitativ forschende. [Practice book interview, transcription \& analysis. instructions and rule systems for qualitative researchers]. 2017. German.

39. Kuckartz U. Qualitative Text Analysis: A Guide to Methods, Practice and Using Software. Sage; 2014.

40. Kuckartz U. Typenbildung. In: Mey G, Mruck K, editors. Handbuch Qualitative Forschung in der Psychologie. [Handbook of Qualitative Research in Psychology]. S Verlag für Sozialwissenschaften; 2010. German.

41. Kluge S. Empirically grounded construction of types and typologies in qualitative social research. Forum Qual Soc Res. 2000;1(1). doi:10.17169/fqs-1.1.1124

42. Ainsworth BE, Haskell WL, Herrmann SD, et al. 2011 compendium of physical activities: a second update of codes and MET values. Med Sci Sports Exerc. 2011;43(8):1575-1581. doi:10.1249/MSS.0b013e 31821 ece 12

43. Deci EL, Ryan RM. The "what" and "why" of goal pursuits: human needs and the self-determination of behavior. Psychol Inq. 2000;11 (4):227-268. doi:10.1207/S15327965pli1104_01

44. Deci EL, Ryan RM. Instrinsic Motivation and Self-Determination in Human Behavior. PLenum Publishing Co; 1985.

45. Patrick H, Williams GC. Self-determination theory: its application to health behavior and complementarity with motivational interviewing. Int J Behav Nutr Phys Act. 2012;9:18. doi:10.1186/ 1479-5868-9-18

46. Skinner EA, Zimmer-Gembeck MJ. Coping. Encyclopedia of Mental Health. 2nd ed. 2016:350-357.

47. Weber M. Wirtschaft Und Gesellschaft: Grundriss der verstehenden Soziologie. [Economy and Society: An Outline of Interpretive Sociology]. Zweitausendeins-Verlag; 2005. German.

48. Bourbeau J, Sedeno M, Li PZ, et al. Mechanisms associated with increased physical activity in patients undergoing self-management behaviour modification in the randomised PHYSACTO trial. ERJ Open Res. 2021;7(1):00533-2020. doi:10.1183/23120541.00533-2020

49. Mesquita R, Spina G, Pitta F, et al. Physical activity patterns and clusters in 1001 patients with COPD. Chron Respir Dis. 2017;14 (3):256-269. doi:10.1177/1479972316687207

50. Donaire-Gonzalez D, Gimeno-Santos E, Balcells E, et al. Benefits of physical activity on COPD hospitalisation depend on intensity. Eur Respir J. 2015;46(5):1281-1289. doi:10.1183/13993003.016992014

51. Armstrong M, Winnard A, Chynkiamis N, Boyle S, Burtin C, Vogiatzis I. Use of pedometers as a tool to promote daily physical activity levels in patients with chronic obstructive pulmonary disease: a systematic review and meta-analysis. Thorax. 2019;74:A105-A105. doi:10.1136/thorax-2019-BTSabstracts2019.172

52. Dobbels F, de Jong C, Drost E, et al. The proactive innovative conceptual framework on physical activity. Eur Respir J. 2014;44 (5):1223-1233. doi:10.1183/09031936.00004814 
53. Lahham A, McDonald CF, Mahal A, et al. Home-based pulmonary rehabilitation for people with COPD: a qualitative study reporting the patient perspective. Chron Respir Dis. 2018;15(2):123-130. doi:10.1177/1479972317729050

54. Blondeel A, Demeyer H, Janssens W, Troosters T. The role of physical activity in the context of pulmonary rehabilitation. Copd. 2018;15(6):632-639. doi:10.1080/15412555.2018.1563060
55. Michie S, Richardson M, Johnston M, et al. The behavior change technique taxonomy (v1) of 93 hierarchically clustered techniques: building an international consensus for the reporting of behavior change interventions. Ann Behav Med. 2013;46(1):81-95. doi:10.1007/s12160-013-9486-6

\section{Publish your work in this journal}

The International Journal of COPD is an international, peer-reviewed journal of therapeutics and pharmacology focusing on concise rapid reporting of clinical studies and reviews in COPD. Special focus is given to the pathophysiological processes underlying the disease, intervention programs, patient focused education, and self management protocols. This journal is indexed on PubMed Central, MedLine and CAS. The manuscript management system is completely online and includes a very quick and fair peer-review system, which is all easy to use. Visit http://www.dovepress.com/testimonials.php to read real quotes from published authors. 